\title{
Cooperative Learning: An Effective Approach to College English Learning
}

\author{
You Lv \\ College of Foreign Languages, Changchun University of Science and Technology, Changchun, China
}

\begin{abstract}
Cooperative Learning (or Collaborative Learning), has become one of mainstream learning strategies in the world. As China continues to push forward and lucubrate into the reform of college English, many educational theorists and teachers who work on college English try to use the cooperative learning, a creative and effective learning strategy, into the current college English learning system, and have made some achievements. This paper also tries to sum up some relevant studies on cooperative learning in college English learning, and use some actual instances of college students' English learning to attempt to raise some effective approaches to improve the cooperative learning strategies in the college English learning, and hope to provide some references for the colleges to launch cooperative learning.
\end{abstract}

Index Terms - cooperative learning, college English, influencing factors

\section{FOREWORD}

Since the Ministry of Education formulated and promulgated the "Requirements for College English Curriculum Teaching" (trial) in 2007, the models of the college English teaching and learning strategies are continuously optimized, and the reform of college English teaching and learning strategies are also constantly deepen and perfect. In accordance with the guidance of the "Requirements" (Ministry of Education, 2007), "one of the purposes of teaching reform is to promote the formation of students' individualized learning methods and the development of students' autonomous learning ability." The new teaching model should be able to make students select suitable materials and methods to learn, attain the guidance of learning strategies, and gradually improve their autonomous learning ability. At the same time, "the teaching reform should ensure that the teaching theory and practice can be changed from the pattern that is teacher-centered and simply to impart knowledge and skills into the pattern that is student-centered and both to teach the knowledge and skills and pay more attention to the cultivation of the practical application of language ability and autonomous learning ability." (Ministry of Education, 2007) This is also a change that aims at the lifelong education whose purpose is to cultivate the students' lifelong learning ability. In the face of such requirements, the college English teaching and learning has received the unprecedented challenge. And at the same time, Cooperative learning which is in accordance with the requirements has attracted more and more attention. Therefore, it is extremely important to discuss how to effectively apply the cooperative learning strategies to the teaching in college English teaching reform.

\section{THE RELATED STUdIES ON COOPERATIVE LEARNING}

\section{A. The Foreign and Domestic Study Status of Cooperative Learning}

From a historical perspective, Cooperative Learning (Collaborative Learning in the studies in the western countries, or the "Collective Teaching" called by Dyachenko in the former Soviet Union) is a relatively old philosophy of education. In the western countries, the source of cooperative learning can be traced back to early human era. As early as in the first century AD, the Roman Quintilian school has pointed out that the students can benefit from the mutual teaching (Shi Aimin \& Pan Li \& Zhou Xiaoqin; 2010). In 1806, the conception of the cooperative learning group was introduced from Britain into the United States, and respected and widely applied by the American educators, like Park, Dewey, etc. The modern theory of cooperative learning was introduced from Britain into America in the 18th century, and was successfully risen and extensively practiced in the 1970s in the United States. The main representative figures of modern cooperative learning include American educator Parke, Professor Dewey and the like. In addition, in the United States, Professor R.E. Slavin at Johns Hopkins University, the brothers Professor D.W Johnson and Professor R.T Johnson at the University of Minnesota, Professor T. R. Guskey at the University of Kentucky, Professor Cagan majored in educational psychology at the University of California--Riverside, and the couple Professor Y. Sharan and S. Sharan at the Tel Aviv University in Israel are all the important representatives in the cooperative learning research and experiment. One of the founders of the cooperative learning theory, Johnson, a professor at the University of Minnesota in the United States, put forward with his members that people could adopt team approach in the teaching in order to make the students have the collaborative efforts and give full play to the advantages of their self-study and peer-study.

Since the 1990s cooperative learning, a new educational conception, along with the reform of Chinese elementary educational curriculum, is gradually favored by the educators, theory workers and especially the front-line teachers. Many theoretical and practical studies have shown that the cooperative learning is obviously effective to improve the 
psychological atmosphere in the classroom, improve the students' academic performance, promote the students' process of socialization, etc. The Education Department of Hangzhou University in Zhejiang province began to experiment the cooperative learning group in the teaching in 1990s. Then in the middle of 1990s Shandong Provincial Institute of Education Research had a series of researches and experiments on the cooperative teaching. In recent years the subjective educational experiments on team cooperation were discussed constantly, and this series of scientific researches on education and teaching practice could promote the development of cooperative learning in China. Professor Wang Tan (2002) who is mainly engaged in cooperative learning combines with Israel R. Sharan' standpoints and points out "cooperative learning is a general term for a series of methods to organize and promote the classroom teaching. In the process of learning among the students, cooperative learning is the basic feature of all these methods. In class, the cooperation between peers is realized by organizing the students in the group activities. The students can learn through the interaction and the communication between peers, also learn through personal study.” Then, the theories and practice of the cooperative learning aiming at the college English teaching, like bamboo shoots after the rain, deepen and perfect in various disciplines and fields of the education in china. However, the current domestic specialized researches and practice on cooperative learning for college English teaching model and learning strategies are not widely available. Therefore, this paper will try to discuss on how to effectively apply cooperative learning strategies to the college English teaching, use the group cooperative learning mode, make full use of the students' and their fellows' advantages in English learning, cultivate students' spirit of cooperation and accomplish their English learning tasks in common. And in the meantime, this paper will also attempt to discuss on how to stimulate students' interest in learning English and improve their enthusiasm for English class activities, so that the students can improve their ability to learn English in the mutual learning and assistance.

\section{B. The Connotation, Elements and Forms of Cooperative Learning}

The connotation of cooperative learning is complex and multi-faceted. The famous Chinese scholar Wang Tan (2001) argued that: "The real cooperative learning is a kind of teaching activity and strategy system which is guided by the teaching goal, organized on the basis of the heterogeneous groups, driven by the power resources from the interactive cooperation of the dynamic factors in the teaching and rewarded for the team achievements." Cooperative learning focuses on the interaction between the teachers and the students and among the students themselves in the process of teaching, and emphasizes on the interactive cooperation among the students in the teaching and learning activities. The interactive cooperation among the students is the common characteristic of cooperative learning. Cooperative learning mainly consists of five basic elements (Song Yu, 2012), including (1)The positive interdependence. The team members depend on and help each other to successfully complete the task; (2)The face-to-face interaction. Team members directly communicate within the team and actively participate in activities to contribute themselves in the maximum; (3)The individual accountability. Team members must develop their individual responsibility in the cooperative learning; (4)The development of social skills within the small group. The social skills in cooperative learning mainly refers to the necessary organizational ability, communicative ability, collaborative ability, respectful attitudes with each other, etc. in the group cooperative learning; (5)The group processing. Team members reflect on the experiences in the group cooperative learning and make best efforts to improve the strategies of the cooperative learning.

With the combination of various teaching characteristics proposed by the advocates and researchers who majored in cooperative learning in recent decades, there are a variety of methods of the cooperative learning produced and applied in educational practice. The most typical and common methods of cooperative learning are listed as follows:

1. Learning Together (LT)

2. The Teams-Games Tournament (TGT)

3. The Group Investigation (GI)

4. Academic Controversy (AC)

5. Jigsaw Learning

6. Student Team-Achievement Divisions (STAD)

7. Team Accelerated Instruction (TAI)

8. The Partner Cooperation (PC)

The styles of the above methods of cooperative learning are not identical, so they are suitable for different types of college English courses. However, as for these types of cooperative methods, the learners must master the different skills in cooperative learning. For example, the learners should grasp how to encourage the others or help others, how to resolve the conflict, how to negotiate, how to reject, etc. (Nan Bo, 2003)

\section{THE Designed TASKS}

The author attempts to use cooperative learning strategies as the main target of the college English classroom teaching in two classes, where the students are in Grade one in the university, and has received the certain effects. Here are two cases of college English classroom teaching combined with the cooperative learning strategies.

\section{A. The Jigsaw Learning}

The main feature of Jigsaw Learning is that the students' learning mostly depends on the cooperation, exchange and 
sharing between the team members form the home group (or Jigsaw group) and the team members from the expert group. Each student will be responsible for the completion of a certain part of the learning task. Teachers are no longer masters of English learning. Instead, they will become collaborators and guide their students to learn. The students will become the real leaders of class learning.

The following case is that the author implemented the cooperative learning strategy, Jigsaw Learning, with the text of "Fighting with the Forces of the Nature" in the textbook College English (new edition) (Shanghai: Shanghai foreign language education press). The time of the designed task is within 90 minutes ( 2 course hours). In the process of the students' cooperative learning with the designed time, there will be several stages as follows.

In the first stage, the students will be divided into the home groups (or Jigsaw groups) for the first time. In the process of the Jigsaw group division in the first time, the teacher should give full consideration to the difference of the students' individual ability. It is best to realize that in the same Jigsaw group there are the students who are excellent in English and also the students who are poor in English. In this way, it is better to arouse the excellent students' enthusiasm and reduce the backward students' anxiety in the process of cooperative learning. When grouping, the teacher should ensure four or five students to form a heterogeneous group. Besides the reasonable division of the group, the teacher should also make the students grasp and practice some skills of the cooperative learning such as lending an ear to, expression, organization, rejection, encouragement and the like. These skills can make sure that the Jigsaw learning activities can be carried out more smoothly and effectively.

In the second stage, the text "Fighting with the Forces of Nature" is divided into several parts and each heterogeneous group receives the learning materials which have already been divided. For instance, the text "Fighting with the Forces of Nature" is mainly concerned about two battles, Napoleon's Campaign to the Russian and Hitler's Invasion to the Soviet Union, and four countries, France, Russia, Germany and the Soviet Union. Therefore, each country will be a learning task. And at the same time, the teacher should help the students to divide the received task again inside the group according to the differences of the individual English ability.

In the third stage, the students will be divided again. The students who have received the same learning materials in different heterogeneous groups will be gathered together to form a new group, an expert group. The students in the same expert group will focus on the same learning materials to learn cooperatively. At this stage of cooperative learning, the students in the expert group must depend on their own strength to learn and grasp the new words and expressions related to their assigned learning materials as much as possible. Each member in the group should actively speak out and participate in discussion, until all the members reach a consensus on the assigned learning tasks and record the achievements of the discussion respectively. At this time, the members have become experts in the assigned reading tasks. At the same time, the students in the same expert group can practice how to interpret the content of the assigned reading material and the new words and expressions in the reading material to the members in their original heterogeneous group. For example, the students who are responsible to learn and master the reading materials about the country, Russia, will begin to discuss and solve the relevant reading tasks, including Russian geography, weather and other natural features in Russia, the military strategies occurred in the text and so on. They also have to help each other to learn and grasp the new words, such as retreat, czar, truce and etc. In this stage, the teacher will no longer play a leading role. When the students have the divergent opinions in the group discussion, the teacher will appropriately help and give advice to them. When the students cannot understand and grasp the new words by themselves, the teacher should give the proper guidance and assistance. When the students report their achievements of their assigned tasks, the teacher should give the appropriate instruction and summary.

In the fourth stage, when all the expert groups have completed their discussion, the students return to the original heterogeneous groups. In a heterogeneous group, each student will take turns to report their achievements of the discussion in the expert group and assist other members to learn and master the assigned reading information. In the process of reporting, the students will also be responsible for the interpretation of the new vocabulary and learning skills to other members. When all the students have completed their reports in their original heterogeneous group, the whole task is completed. For instance, when the students return their heterogeneous group to share and study the information by turns, such as the military strategies adopted by France, Russia, Germany and the Soviet Union, the natural conditions and so forth. The group members should complete the relevant reading task about the country that they have been assigned. In this stage, the teacher should walk around each group, observe how the group tasks progress and give some guidance and suggestions. At the same times, the teacher should record and evaluate the process and achievements of each group's cooperative learning.

The author finds out that when the teacher has explained the objectives and procedures of the English cooperative learning clearly, although there are still some difficulties in learning, the students are pleased to participate in this English learning strategy in class which breaks the traditional PPP (presentation, practice, production) (Zhang Pei, 2009), and find fun in the process of Jigsaw learning.

\section{B. Learning Together}

Learning together (LT) in particular refers to the method in which four or five students of different English proficiency comprise a group and study together to complete a task. At the end of learning together, each group should submit an assignment to the teacher and will be rewarded according to the achievements of the group performance. This method emphasizes on that the whole group can improve the ability to interact and cooperate with others through the 
group common activities, such as discussion, brainstorming, reflection, and so on. However, the brothers Professor D.W Johnson and Professor R.T Johnson did not provide a specific operation method, but beyond the research approaches to the specific teaching methods, they systematically put forward the five elements of the effective cooperative learning. Learning together is an early and universal method of cooperative learning.

The author once tried to use learning together method to design a 30-minute writing task in the college English course. The whole procedure of learning together method can be composed of three stages, including pre-writing, in-writing and language focus. And the specified time is within 30 minutes. With the help of the writing skills that the students have mastered in class, the students should cooperate and complete a composition in the group, and hand in it in written form. And then the author will give a comment on the achievements of each group. Before the procedure, the whole students will be divided into several writing groups, mainly each of which should consist of four or five students.

In the pre-writing stage, the teacher will introduce the topic of the task to the whole students at the beginning. The topic of the composition is "Success". Then the teacher will lead the students to collect the materials, such as the examples of the famous successful celebrities, some well-known old sayings related to success and so on. In the meanwhile the teacher also guide the students to conceive and draw up the outline, identify the main ideas and etc. through their discussion and negotiation, with the joint efforts of the group.

In the in-writing stage, based on individual ability and the interest, the members will have the division of labor on all the assignments agreed within the group, such as screening and organizing the materials, forming the outline and content of the draft, selecting the correct words, phrases and sentence patterns, amending the errors, and the like. Every member inside the group will receive one or two specific assignments. In this stage, the teacher should make the students express themselves in a relaxing atmosphere. In order to make the students to have more confidence, the teacher could show some sample compositions, but encourage the students to use their imagination and creativity to compose in stead of imitating those samples.

In the third stage, the team members will discuss, negotiate and modify the draft together. They should thresh whether the theme is outstanding, whether the paragraphs are reasonable and coherent, whether it is appropriate to use such words or phrases and so on. And the teacher could encourage students to read the draft in the small scope and make them give advice and evaluation. In the end, each group should hand in their final composition in the specified time and the teacher should give some suggestions and evaluation to the group achievements.

The author finds out that, when the teacher has explained the learning objectives and procedures to the students clearly, the students are willing to try and cooperate, and finally find joy in the process the learning together method. In addition, in the whole process the teacher needs to observe around all the groups, guide and supervise the task progress and result of each group. When there is misrepresentation and lack of words occurred, the teacher should guide and help the students correctly and cautiously. When each group has completed the task and submits their compositions, the teacher must record and evaluate the outcomes of the cooperate learning in each group.

\section{The Influencing Factors of College English CoOPERATIVE LEARning}

In the author's opinion, the effects of the cooperative learning strategies are quite obvious in the process of the college English learning. In the process of English learning, the cooperative learning strategy not only can be beneficial to help to reduce the students' anxiety, but also can increase the students' self-confidence, bring their enthusiasm, initiative, imagination and creativity. At the same time, it also can provide a good platform for the college students, which is conducive to the students about forming good learning and communicative skills and cultivating the students' consciousness to cooperate and help with each other. Combined with the practical teaching experience and some points of view from the researchers who major in the cooperative learning theories, the author thinks that the chief factors that can affect the cooperative learning strategies to play a main role in the college English learning are as follows:

1. The teachers need to have a positive attitude towards the cooperative learning strategy. They should have in-depth understanding and grasp on the connotation, characteristics and skills of cooperative learning, and also they need to have an abundant store of knowledge. Teachers' role in the cooperative learning process mainly is to guide and supervise. But at the same time because of the need to guide and supervise in the whole process of cooperative learning, as a result, it is essential for the teachers to explicitly study and master the connotation and necessary skills of cooperative learning. In the process of cooperative learning, teachers should define the purpose and task of cooperative learning, and give clear instructions to the students. They should explain clearly to the students about the activities of cooperative learning, concerning the intention, requirements, methods, steps, etc., in order to avoid students to be at a loss. At the same time, the teachers should be able to control the time of cooperative learning. And according to the difficulty of the tasks and the actual situation where the students discuss, they should decide when to stop. In addition, the teachers should guide their students to learn cooperative skills in the process of cooperative learning. In the process of mutual learning, the teachers should delve into the students' activities to listen and observe the group behavior, pay attention to the problems of the completion of the tasks or the process of cooperation, and timely provide the effective guidance and assistance for the students. In the meanwhile, they also should lead the groups to focus on the existing problems and try to let the students find their own rules and solve problems. Then, the teachers need to give the students the opportunity to fully display the achievements and give timely feedback and summary. They could try to make more groups to fully show their achievements respectively, and make the students understand that what they are speaking out 
is on behalf of the group opinions rather than personal thoughts. They also remember to encourage and inspire their students to put forward different views on the issue, debate with each other, and stimulate the students to have in-depth thinking. At the same time, the teachers should have self-reflection in the learning and the practice, constantly adjust their learning strategies and restructure or rearrange the students' English learning content, in order to make sure that the English classroom learning strategies are conducive to the mutual development between teachers and students.

2. Faced with the cooperative learning strategies, the students need to have the psychological preparation and communication skills. The Students' role in the process of cooperative learning is not only to be the participants, but also to be specific organizer and designer of the activities. Therefore, the students' learning attitude and devotion to the activities will affect the students' learning in the overall cooperation. In addition, the most basic condition for the cooperative learning is that the task is completed by the members within the group. Therefore, it is essential for the students to master the necessary cooperative skills in cooperative learning. In the process of cooperative learning, the students should learn to ponder seriously, actively speak, actually participate in English classroom learning, actively explore the formation process of new knowledge, and use their own expressions to show the process of exploration. Communicating within the group, the students can find out different views of from their own to solve the problems, and can help those students who have difficulty in learning English, with a group spirit of cooperation. In addition, the students must learn to listen to others' opinions modestly. The behavior of each member in the group will be advised, reminded and corrected from others. Therefore, they need to hear and record others' views carefully, and compare others' views with their own views, and even dare to deny themselves. At the same time, the students should also learn to actively practice, the actual hands-operated practice. Knowledge results from practice, and learning knowledge is also inseparable from the practical operation. Finally, the students should learn to practice cooperatively and combine the practice with thinking. The activities in cooperative learning should reflect the consciousness of cooperation, that is to say, it can not only reflect the wisdom of the collective, but also cultivate the students' consciousness of cooperation and form the habit of working with people. In the psychological atmosphere where the students can call a spade a spade, actively cooperate and have a harmonious understanding with others in the group, the students' creative potential can be brought into full play, so as to promote students' cooperative ability.

3. According to the different types of cooperative learning, there should be diverse kinds of the reasonable and effective evaluation mechanism. Whether a cooperative learning strategy is feasible and effective to achieve the expected objectives can be referred from the effective data of the scientific evaluation mechanism. It is better to achieve the goal of promotion through evaluation, with cooperative learning evaluated effectively. The evaluation of cooperative learning should include self-evaluation, peer-evaluation, group-evaluation and teacher-evaluation. The process of the evaluation should adhere to an integrated standard. For instance, it is based on the group performance. The individual performance should be combined with the group performance, and the skill performance is united with the cooperation performance in the group. Through the grasp of the state of the students' real classroom learning and activities, the teachers can collect all kinds of information, timely find problems and improve, in order to promote the benign development of cooperative learning. On the evaluation content, the teachers should pay attention to the students' emotion, attitude, ability, the language expression and the potential for self-development in the process of cooperative learning to conduct a comprehensive evaluation mechanism. In the "Requirements for College English Curriculum Teaching" (trial) it is clearly pointed out that "The system of evaluation includes two forms, formative evaluation and summative evaluation, and the colleges and universities should actively introduce diversified evaluation system according to the characteristics of college education."(Ministry of Education, 2007) The evaluation mechanism of cooperative learning in the college English teaching should be an evaluation system combined the formative evaluation with summative evaluation, and should be aimed at college students' English learning process and the results, based on the evaluation of students' ability to practically apply in English.

\section{CONCLUSION}

From the perspective of the development of modern foreign language teaching in China, college English teaching and learning is constantly reforming and diversifying. The author shows that the cooperative learning strategies have a positive effect on the college English learning through the real samples of the college English classroom learning. But at the same time, the author also believes that the effective cooperative learning strategies can be implemented in combination with other forms of teaching. The Strategies differ from person to person, due to the circumstances. As a kind of effective learning strategies and learning style, cooperative learning can not only promote the college students' acquisition of language knowledge, language skills and the development of communicative competence, but also help to promote the students' positive enterprising, learn to cooperate, cultivate the students' consciousness of the innovation and the spirit of cooperation. In the meanwhile, it also can exercise the students' practical ability and improve their comprehensive quality, so as to promote the college students' employment competitiveness and sustainable development to lay a necessary foundation for the future. In the end, the author hopes that this paper can be useful to expend the teaching methods for the majority of college English teachers and provide the effective ways to enrich the content of college English classroom teaching. 


\section{REFERENCES}

[1] Ministry of Education. (2007). Requirements for College English Curriculum Teaching (trial). Shanghai: Shanghai Educational Press.

[2] Nan Bo. (2003). On cooperative learning and its application in the EFL class. Journal of Sichuan International Studies University, 1, 150-152.

[3] Shi Aimin. \& Pan Li. \& Zhou Xiaoqin. (2010). The teaching mode of college English cooperative learning. Journal of Social Science of Hunan Medical University, 4, 93-95.

[4] Song Yu. (2012). Application of cooperative learning in the college task-based English teaching. Journal of Exam Week, 27, 83-84.

[5] Wang Tan. (2001). Cooperative Learning--the Principle and Strategy. Beijing: Xueyuan Press.

[6] Wang Tan. (2002). On the basic concepts of cooperative learning. Educational research, 2, 68-72.

[7] Zhang Pei. (2009). Collaboration tasks: an effective means of vocabulary learning. Foreign Language and Their Teaching, 12 , $37-40$.

[8] Zeng Qi. (2002). Reflection and prospect of cooperative learning research. Journal of Education theory and practice, 3, 50-53.

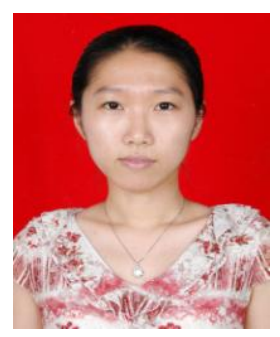

You Lv was born in Changchun, China, in 1981. In 2006, You Lv obtained her master's degree in the filed of English Curriculum and Teaching Methodology in Northeast Normal University in Changchun, China.

She is a Lecturer in College of Foreign Languages, Changchun University of Science and Technology, China. She has published several articles and joined in to edit several books, such as Educational Assessment in High School (Changchun: Northeast Normal University Press, 2005). Her major field of study mainly involves English curriculum and teaching methodology and pedagogy. 